\title{
XÁC ĐİNH HÀM LƯợNG CRINAMIDIN TRONG MộT SỐ THỰC PHẨM CHỨC NĂNG BẰNG GC-MS/MS
}

Lê Thị Liên ${ }^{1}$, Bạch Thúy Anh², Cao Công Khánh ${ }^{2}$, Trần Nguyên Hà̀ ${ }^{1}$, Lê Thị Hồng Hảo

${ }^{1}$ Truờng đại học Dược Hà Nội

${ }^{2}$ Viện Kiểm nghiệm an toàn vệ sinh thực phẩm Quốc gia

(Ngày đến tòa soạn: 22/1/2018; Ngày sưa bài sau phản biện: 2/3/2018; Ngày chấp nhận đăng: 9/3/2018)

Tóm tắt

PHUONG pháp xác định hàm luợng Crinamidin bằng sắc ký khí khối phổ hai làn (GC-MS/MS) đã được xây dựng và thẩm định trên nền mẫu thực phẩm chức năng. Phuơng pháp được thực hiện trên cột DB5-MS, kết hợp với detector khối phổ ba tứ cưcc. Phuơng pháp được đánh giá về độ đặc hiệu, đuờng chuẩn, độ đúng, độ chụm, giới hạn phát hiện (LOD) và giới hạn định luợng (LOQ). Đường chuẩn được xây dựng trong khoảng nồng độ tù 5ppm-50ppm với hệ số tương quan là 0,9970. Độ thu hồi với ba mức nồng độ đều đạt trên 90,1\%. Giới hạn phát hiện và giới hạn định lượng của phuơng pháp lần luợt là 3 và $10 \mathrm{mg} / \mathrm{kg}$. Tất cả các kết quả thu được đều đáp ứng yêu cầu của $A O A C$ trên nền mẫu thực phẩm chức năng. Phương pháp được ưng dụng để phân tích 34 mẫu thực tế trên địa bàn Hà Nội.

Tù khóa: Crinamidin, sắc ký khí khối phổ hai lần (GS-MS/MS)

\section{I. ĐẠTT VẤN ĐỀ}

Trinh nữ hoàng cung (TNHC) là loại dược liệu được sử dụng ngày càng nhiều tại Việt Nam. Đã có nhiều công trình nghiên cứu chứng minh được các tác dụng của TNHC trên u xơ tử cung, ung thư vú, ung thư tuyến tiền liệt, dạ dày, phổi [2]. Ngoài ra TNHC còn có khả năng chống ngưng kết tiểu cầu, chống độc tế bào, ức chế sự hình thành mạch máu của các tế bào nội mô tĩnh mạch rốn ở người (HUVECs) và điều hòa hệ miễn dịch của cơ thể. Hiện nay thực phẩm chức năng chứa TNHC xuất hiện trên thị trường rất phong phú và đa dạng. Việc tiêu chuẩn hóa chế phẩm đóng vai trò vô cùng quan trọng trong kiểm soát chất lượng. Crinamidin là alkaloid đại diện được lựa chọn để xác định hàm lượng nhằm đánh giá tiêu chuẩn của chế phẩm. Mặc dù trong Dược điển Việt Nam đã có phương pháp xác định hàm lượng Crinamidin bằng HPLC trên nền mẫu dược liệu, tuy nhiên vẫn gặp những khó khăn trong quá trình phân tích do hạn chế về độ nhạy và độ đặc hiệu, nhất là trên nền mẫu phức tạp như thực phẩm chức năng. Trong nghiên cứu này, chúng tôi xây dựng phương pháp nhằm xác định hàm lượng Crinamidin trong các sản phẩm thực phẩm chức năng bằng sắc ký khí khối phổ hai lần (GC-MS/MS). Từ đó góp phần kiểm soát chất lượng của các chế phẩm TNHC trên thị trường, nâng cao hiệu quả cho người sử dụng.

\section{II. ĐỐI TƯợNG VÀ PHƯỚNG PHÁP NGHIẾN CỨU}

\section{1. Đối tượng nghiên cứu}

Đối tượng nghiên cứu là Crinamidin.

Mẫu được sử dụng trong nghiên cứu là các thực phẩm chức năng: viên nang cứng, trà túi lọc.

\subsection{Thiết bị và dụng cụ}

Thiết bị phân tích sử dụng trong nghiên cứu là hệ thống GC-MS/MS gồm máy GC 7890A và khối phổ MS 7000B (ba tứ cực) của Agilent. Cột sắc ký khí DB5MS (30m x 0,25mm x 0,25 $\mu \mathrm{m})$ được sử dụng để phân tích Crinamidin.

\subsection{Hóa chất và chất chuẩn}

- Dung dịch chuẩn Crinamidin $200 \mu \mathrm{g} / \mathrm{mL}$ (Bộ môn Hóa phân tích kiểm nghiệm, Trường Đại học y dược thành phố Hồ Chí Minh, 93,1\%) được pha trong chloroform, bảo quản ở 2-8 ${ }^{\circ} \mathrm{C}$.

- Nội chuẩn (IS) Cafein $1000 \mu \mathrm{g} / \mathrm{mL}$ (Viện Kiểm nghiệm thuốc trung ương), được pha trong chloroform, bảo quản ở 2-8 $8^{\circ} \mathrm{C}$. 
- Các dung môi gồm chloroform, methanol, acid hydrochloric, ammoniac thuộc loại tinh khiết phân tích (Merck).

\subsection{Phương pháp nghiên cứu}

\subsubsection{Phương pháp xủ lý mẫu}

Đồng nhất mẫu: Viên nang cứng, lấy 20 viên, loại bỏ vỏ nang và gộp mẫu đồng nhất.

Nền mẫu thực phẩm chức năng là nền mẫu rất phức tạp do chứa nhiều loại dược liệu khác nhau và các tá dược nên việc lựa chọn dung môi chiết và quy trình xử lý mẫu là rất quan trọng. Crinamidin là một alkaloid, ở dạng bazơ tan tốt trong dung môi hữu cơ, không tan trong nước; khi chuyển sang dạng muối lại tan tốt trong nước và không tan trong dung môi hữu cơ. Vì vậy, chúng tôi đã dựa trên tính chất này và tham khảo các tài liệu $[1,2,4,5]$ để chiết Crinamidin ra khỏi nền mẫu.

Quá trình đun hồi lưu mẫu: các điều kiện về dung môi chiết, thời gian và số lần chiết được khảo sát lựa chọn quy trình chiết Crinamidin tối ưu.

Nhóm nghiên cứu sử dụng phương pháp chiết lỏng - lỏng để loại tạp và làm giàu mẫu.

\subsubsection{Phưong pháp sắc ký khi khối phổ hai lần}

Crinamidin và nội chuẩn Cafein được tối ưu sử dụng nguồn ion hóa va chạm electron $(\mathrm{EI})$, chế độ quét lựa chọn đa phản ứng $(\mathrm{MRM})$. Mỗi chất chọn ion mẹ và thực hiện tối ưu các điều kiện phân mảnh để chọn ra 2-3 ion con, 1 ion được sử dụng để định lượng và ion còn lại được sử dụng để xác nhận. Điều kiện GC được khảo sát trên cột sắc ký DB5-MS.

\section{KẾT QUẢ VÀ BÀN LUÂN}

\subsection{Khảo sát các điều kiện tối ưu để phân tích Crinamidin bằng GC-MS/MS}

Sử dụng dung dịch chuẩn 10 ppm để thực hiện khảo sát các điều kiện tối ưu trên khối phổ. Crinamidin được lựa chọn 3 ion con. Nội chuẩn Cafein được lựa chọn 2 ion con. Một ion được sử dụng để định lượng, ion còn lại được sử dụng để khẳng định. Các kết quả xác định được tóm tắt trong bảng 1 .

Bảng 1. Thời gian lư và điều kiện MS/MS để phân tích Crinamidin

\begin{tabular}{|c|c|c|c|c|c|c|}
\hline$S T T$ & Hơp chất & $\begin{array}{l}\text { Thòi gian } \\
\text { luu (phút) }\end{array}$ & Ion me $(m / z)$ & Ion $\operatorname{con}(\mathrm{m} / \mathrm{z})$ & $\begin{array}{c}\text { Năng luợng } \\
\text { bắn phá } \\
\text { (eV) }\end{array}$ & Ghi chú \\
\hline \multirow{3}{*}{1} & \multirow{3}{*}{ Crinamidin } & \multirow{3}{*}{16,7} & 317 & 217 & 30 & Định lượng \\
\hline & & & 317 & 244 & 25 & Xác nhận \\
\hline & & & 317 & 288 & 20 & Xác nhận \\
\hline \multirow{2}{*}{2} & \multirow{2}{*}{$\begin{array}{l}\text { Cafein } \\
\text { (IS) }\end{array}$} & \multirow{2}{*}{8,0} & 194 & 82 & 30 & Định lượng \\
\hline & & & 194 & 109 & 25 & Xác nhận \\
\hline
\end{tabular}

Crinamidin được tách qua cột sắc ký khí DB5-MS với các thông số như sau: Nhiệt độ buồng tiêm mẫu $250^{\circ} \mathrm{C}$, chế độ tiêm mẫu chia dòng (10:1). Khí mang Heli, tốc độ dòng $1,0 \mathrm{~mL} / \mathrm{phút}$. Chương trình nhiệt độ: nhiệt độ ban đầu $100^{\circ} \mathrm{C}$ (giữ trong 1 phút), tăng $20^{\circ} \mathrm{C} /$ phút lên $240^{\circ} \mathrm{C}$ (giữ trong 1 phút), tăng $5^{\circ} \mathrm{C} /$ phút lên $290^{\circ} \mathrm{C}$ (giữ trong 6 phút). Tổng thời gian phân tích là 27 phút. Nguồn ion hóa $\mathrm{EV}$ là $70 \mathrm{eV}$, với nhiệt độ nguồn ion là $270^{\circ} \mathrm{C}$. Hình 1 giới thiệu sắc đồ của chuẩn Crinamidin và nội chuẩn Cafein tại nồng độ 10 ppm.

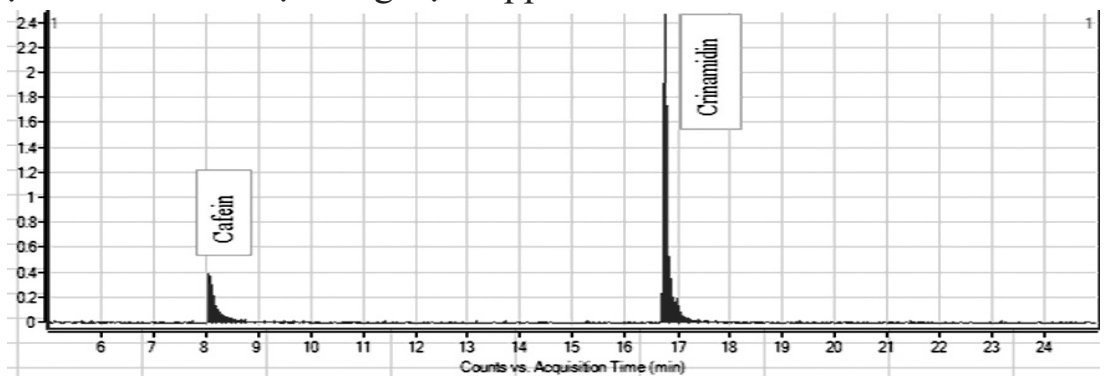

Hình 1. Sắc đồ tổng (TIC) chuẩn Crinamidin và nội chuẩn Cafein tại nồng độ 10 ppm 


\subsection{Khảo sát quy trình xử lý mẫu}

Mẫu được kiềm hóa bằng dung dịch amoniac, sau đó đun hồi lưu với hỗn hợp dung môi hữu cơ. Sử dụng các dung môi với các $\mathrm{pH}$ khác nhau để loại tạp. Sau đó mẫu được làm giàu và phân tích trên GC-MS/MS.

Trong quá trình xử lí mẫu trên, loại dung môi chiết, thời gian và số lần đun hồi lưu mẫu ảnh hưởng đến hiệu suất chiết đã được khảo sát và tối ưu.

Lựa chọn dung môi chiết mẫu

Tiến hành khảo sát dung môi chiết với 100\% methanol và hỗn hợp dung môi chiết chloroform: methanol ở các tỷ lệ: 1:3, 1:1, 3:1 (v/v), nhận thấy khi sử dụng hỗn hợp chloroform : methanol (3:1) cho tín hiệu cao nhất trong quá trình phân tích.

Lựa chọn số lần và thời gian đun hồi lưu mẫu

Crinamidin được chiết ra khỏi mẫu bằng kĩ thuật chiết hồi lưu với hệ dung môi chloroform: methanol (3:1) (v/v). Các yếu tố cần khảo sát gồm: số lần và thời gian đun hồi lưu mẫu. Số lần chiết 1 lần, 2 lần, 3 lần với thời gian đun 60 phút và thời gian đun 30 phút, 60 phút, 90 phút và 120 phút đã được khảo sát. Kết quả cho điều kiện tối ưu là đun hồi lưu mẫu 2 lần, mỗi lần 60 phút.

Quy trình chiết mẫu tối ưu như sau:

Cân chính xác khoảng 1-5 g mẫu đã đồng nhất vào bình cầu $250 \mathrm{~mL}$. Kiềm hóa mẫu đến $\mathrm{pH}=9$ bằng dung dịch ammoniac đặc, để yên 60 phút. Thêm $100 \mathrm{~mL}$ hỗn hợp dung môi chloroform : methanol $(3: 1)$ vào bình cầu và đun hồi lưu trong 60 phút. Gạn dịch chiết vào bình cô quay là đun hồi lưu lần 2. Gộp dịch chiết và cô mẫu đến cắn. Hòa cắn trong $20 \mathrm{~mL}$ acid chlohydric $0,1 \mathrm{~N}$ và chuyển vào ống ly tâm $50 \mathrm{~mL}$. Thêm $20 \mathrm{~mL}$ chloroform, lắc ngang 30 phút, ly tâm 6000 vòng/phút trong 5 phút, loại bỏ dịch chloroform. Kiềm hóa dịch acid đến $\mathrm{pH}=9,4$ bằng dung dịch ammoniac. Thêm $15 \mathrm{~mL}$ chloroform vào ống ly tâm, lắc ngang 30 phút. Mẫu sau đó được ly tâm 6000 vòng/phút trong 5 phút. Thu lấy phần dịch chloroform vào bình định mức $25 \mathrm{~mL}$. Chiết lặp lần 2 với $8 \mathrm{~mL}$ chloroform. Gộp dịch chiết, thêm $0,1 \mathrm{~mL}$ nội chuẩn cafein $125 \mu \mathrm{g} / \mathrm{mL}$ và định mức đến vạch bằng chloroform. Lọc dịch và phân tích bằng GC-MS/MS.

\subsection{Thẩm định phương pháp phân tích}

\subsubsection{Tính đặc hiệu/chọn lọc}

Trong nghiên cứu này, Crinamidin được đặc trưng bởi 1 ion mẹ và 2 ion con, do đó số điểm IP là 4 đạt yêu cầu của $\mathrm{EC}$ về nhận dạng pic. Ngoài ra, trên mẫu thêm chuẩn có xuất hiện các pic với thời gian lưu tương tự trên chuẩn; trên mẫu trắng không thấy có pic của Crinamidin. Hình 2 minh họa phổ khối của chuẩn Crinamidin và nội chuẩn Cafein.

Phổ khối của Crinamidin

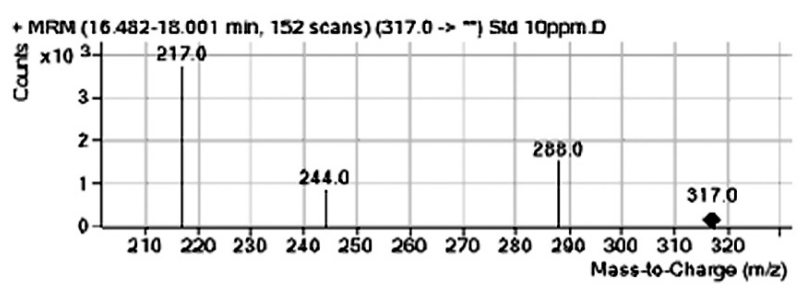

\section{Phổ khối của Cafein}

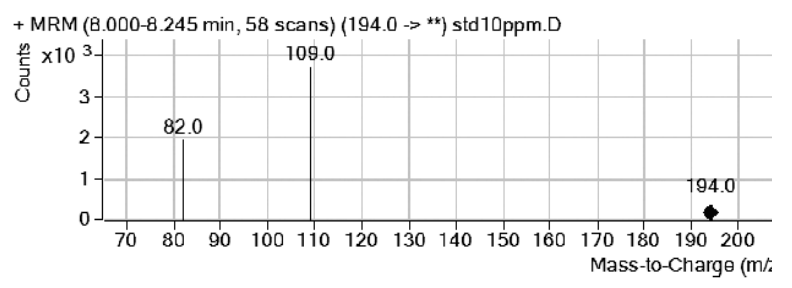

Hình 2. Phổ khối của chuẩn Crinamidin và nội chuẩn Cafein

\subsubsection{Giới hạn phát hiện (LOD), giới hạn định lượng (LOQ)}

LOD, LOQ của phương pháp được xác định bằng cách phân tích các mẫu trắng thêm chuẩn ở nồng độ thấp để thu được tỷ số tín hiệu trên nhiễu $(\mathrm{S} / \mathrm{N})$ tương ứng là 3 và 10 . Kết quả thu được $L O D$ và $L O Q$ tương ứng là $3 \mathrm{mg} / \mathrm{kg}$ và $10 \mathrm{mg} / \mathrm{kg}$. Hình 3 thể hiện sắc đồ của Crinamidin tại mức LOQ. 


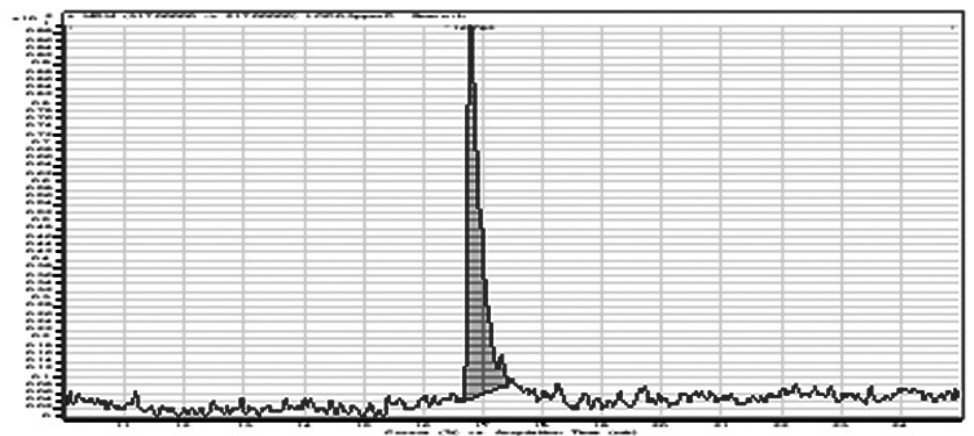

\section{Hình 3. Giới hạn dịnh luợng (LOQ) của Crinamidin}

\subsubsection{Xây dựng đường chuẩn}

Đường chuẩn của Crinamidin được xây dựng từ $5-50 \mu \mathrm{g} / \mathrm{mL}$, diện tích pic phụ thuộc tuyến tính vào nồng độ theo phương trình $\mathrm{y}=0,089074 \mathrm{x}-0,44413$ với hệ số biến thiên $\mathrm{R}^{2}=0,9970$.

\subsection{4. Độ lặ lại}

Để khảo sát độ lặp lại của phương pháp, phân tích lặp lại 6 lần đối với các mẫu TPCN dạng viên nang cứng và dạng trà túi lọc. Đây là 2 nền mẫu chủ yếu có chứa Crinamidin trên thị trường. Xử lý mẫu và tiêm mẫu vào máy GC-MS/MS theo các điều kiện đã khảo sát. Độ lặp lại của phương pháp được đánh giá thông qua hệ số biến thiên RSD (\%).

Các kết quả thu được cho thấy phương pháp có độ chụm tốt với hệ số biến thiên RSD (\%) nằm trong khoảng từ $4,5 \%$ - 4,9\% đều đạt yêu cầu của $\mathrm{AOAC}$.

\subsection{5. Độ thu hồi}

Độ đúng của phương pháp được đánh giá bằng cách thêm chuẩn ở 3 nồng độ khác nhau $(80 \%$, $100 \%, 120 \%$ so với hàm lượng mẫu thực) trên nền mẫu $\mathrm{TPCN}$ dạng viên nang cứng và đánh giá hiệu suất thu hồi. Kết quả thể hiện trong bảng 2.

Bảng 2. Kết quả phân tích độ thu hồi của Crinamidin trên nền mẫu viên nang cứng

\begin{tabular}{|c|c|c|}
\hline Crinamidin/mẫu $(\mu g / g)$ & Khối lựng chuẩn thêm vào ( $\mu$ g) & Độ thu hồi (\%) \\
\hline \multirow{3}{*}{82,4} & 160 & $90,1-96,0$ \\
\hline & 200 & $91,5-97,2$ \\
\hline & 240 & $92,8-99,4$ \\
\hline
\end{tabular}

Kết quả phân tích có độ thu hồi R\% nằm trong khoảng từ 90,1\% - 99,4\%, cho thấy phương pháp có độ đúng đáp ứng được theo yêu cầu của AOAC.

\section{4. Áp dụng phương pháp tiến hành phân tích một số mẫu trên thị trường}

Kết quả phân tích hàm lượng Crinamidin trên 29 mẫu thực phẩm chức năng và 5 mẫu nguyên liệu được lấy trên địa bàn Hà Nội chỉ ra ở bảng 3 và bảng 4 .

Bảng 3. Hàm lượng Crinamidin trên 29 mẫu thực phẩm chức năng

\begin{tabular}{|c|c|c|}
\hline STT & Mẫu thực & Hàm lượng $(\boldsymbol{\mu g}$ /viên) \\
\hline 1 & M1 (viên nang cứng) & 206,9 \\
\hline 2 & M2 (viên nang cứng) & 45,0 \\
\hline 3 & M3 (viên nang cứng) & $(-)$ \\
\hline 4 & M4 (viên nang cứng) & 40,1 \\
\hline 5 & M5 (viên nang cứng) & 33,4 \\
\hline 6 & M6 (viên nang cứng) & 42,2 \\
\hline 7 & M7 (viên nang cứng) & 19,5 \\
\hline 8 & M8 (viên nang cứng) & 18,3 \\
\hline 9 & M9 (viên nang cứng) & 35,6 \\
\hline 10 & M10 (viên nang cứng) & 103,8 \\
\hline 11 & M11 (viên nang cứng) & $(-)$ \\
\hline 12 & M12 (viên nang cứng) & $(-)$ \\
\hline 13 & M13 (viên nang cứng) & 42,9 \\
\hline 14 & M14 (viên nang cứng) & 94,9 \\
\hline
\end{tabular}

\begin{tabular}{|c|c|c|}
\hline 15 & M15 (viên nang cứng) & $(-)$ \\
\hline 16 & M16 (viên nang cứng) & $(-)$ \\
\hline 17 & M17 (viên nang cứng) & $(-)$ \\
\hline 18 & M18 (viên nang cứng) & $(-)$ \\
\hline 19 & M19 (viên nang cứng) & 60,2 \\
\hline 20 & M20(viên nang cứng) & 105,3 \\
\hline 21 & M21 (viên nang cứng) & 54,0 \\
\hline 22 & M22 (viên nang cứng) & $(-)$ \\
\hline 23 & M23 (viên nang cứng) & 223,7 \\
\hline 24 & M24 (viên nang cứng) & 117,8 \\
\hline 25 & M25 (viên nén) & 110,5 \\
\hline 26 & M26 (viên nén) & $(-)$ \\
\hline 27 & M27 (viên nén) & 181,4 \\
\hline 28 & M28 (viên nén) & 54,6 \\
\hline 29 & M29 (viên nén) & \\
\hline
\end{tabular}

Chú thich: (-): không phát hiện

\section{6 | Tạp chí KIỂM NGHIỆM VÀ AN TOÀN THỰC PHẨM (Số1-2018)}


Bảng 4. Hàm lương Crinamidin trên 5 mẫu nguyên liệu

\begin{tabular}{|c|c|c|}
\hline STT & Mẫu thục & Hàm luọng (mg/100g) \\
\hline 1 & Nguyên liệu 1 (cao khô) & 14,2 \\
\hline 2 & Nguyên liệu 2 (cao phun sấy) & 0,065 \\
\hline 3 & Nguyên liệu 3 (cao lỏng) & 0,26 \\
\hline 4 & Nguyên liệu 4 (cao khô) & 1,56 \\
\hline 5 & Nguyên liệu 5 (cao khô) & 6,33 \\
\hline
\end{tabular}

Qua khảo sát sơ bộ 29 mẫu thực phẩm chức năng trên thị trường cho thấy hàm lượng Crinamidin dao động trong khoảng từ 18,3 $\mu \mathrm{g} / \mathrm{viên}$ đến $381,4 \mu \mathrm{g} / \mathrm{viên}$, trong có 10 mẫu không phát hiện được Crinamidin. Đối với các mẫu nguyên liệu, hàm lượng Crinamidin dao động trong khoảng từ 0,065 $\mathrm{mg} / 100 \mathrm{~g}$ (mẫu phun sấy) đến $14,2 \mathrm{mg} / 100 \mathrm{~g}$ (mẫu cao khô). Điều này cho thấy chất lượng nguyên liệu ban đầu trước khi đưa vào sản xuất cũng không đồng đều. Trong khi đó, hầu hết các sản phẩm TPCN chứa trinh nữ hoàng cung chỉ công bố trên nhãn về hàm lượng cao nguyên liệu. Do đó, cần thiết phải tiêu chuẩn hóa nguyên liệu TNHC để người tiêu dùng có thể lựa chọn sản phẩm phù hợp, có chất lượng.

\section{KẾT LUẠN}

Phương pháp xác định Crinamidin trong thực phẩm chức năng đã được xây dựng gồm quy trình chiết mẫu và quy trình phân tích Crinamidin bằng $\mathrm{GC}-\mathrm{MS} / \mathrm{MS}$. Phương pháp này sử dụng nội chuẩn Cafein giúp các kết quả phân tích chính xác và ổn định hơn. Phương pháp cũng đã được thẩm định về độ đặc hiệu, đường chuẩn, độ lặp lại, độ chính xác và giới hạn phát hiện. Kết quả thẩm định phương pháp cho thấy quy trình đã xây dựng phù hợp để áp dụng nhằm xác định hàm lượng Crinamidin trong thực phẩm chức năng.

\section{TÀI LIẸU THAM KHẢO}

1. Bộ Y Tế Dược điển Việt Nam IV Bản bổ sung, NXB Y học, Hà Nội, 2015, pp. 1182 - 1184.

2. Đỗ Tất Lợi, Những cây thuốc và vị thuốc Việt Nam, NXB Y học, Hà Nội, 2015, pp. 510 - 512.

3. Võ Thị Bạch Huệ, Nguyễn Khắc Quỳnh Cứ, Ngô Vân Thu, Delome Frederic, Daniel F. Michel Bechi, "Khảo sát alcaloid chiết từ lá cây Trinh nữ hoàng cung (Crinum latifolium L. Amaryllidaceae) bằng kỹ thuật GCMS", Tạp chí Dược học, 4, 1999, pp. 9-11.

4. Nguyễn Hữu Lạc Thủy, Nguyễn Hồng Thiên Thanh, Võ Thị Bạch Huệ, "Phân lập và xây dựng chất chuẩn crinamidin từ lá trinh nữ hoàng cung Crinum latifolium L.", Tạp chí Dược học, 441, (2013), pp. 38 - 41.

5. John Refaat, Mohamed S. Kamel, Mahmoud A. Ramadan and Ahmed A. Ali, "Crinum; an endless source of bioactive principles: A review. Part V. Biological profile", International journal of pharmaceutaical sciences and research, 4 (4), 2013, pp. 1239 - 1252.

Summary

\section{DETERMINATION OF CRINAMIDINE IN DIETARY SUPPLEMENTS BY GC-MS/MS.}

\section{Le Thi Lien ${ }^{1}$, Bach Thuy Anh², Cao Cong Khanh², Tran Nguyen $\mathrm{Ha}^{1}$, Le Thi Hong Hao ${ }^{2}$}

${ }^{1}$ Hanoi University of Pharmacy

${ }^{2}$ National Institute for Food Control

The determination of crinamidine in dietary supplements content by mass spectrometry $(G C-M S / M S)$ was developed and validated. The method was performed on the DB5MS column (30m $\times 0,25 \mathrm{~mm} ; 0,25 \mu \mathrm{m})$, in combination with the tandem mass spectrometry. The parameters of the method were evaluated for selectivity, calibration curve, accuracy, precision, limit of detection (LOD) and limit of quantification (LOQ). The calibration curve was highly linear (the coefficient of determination 0.9970) within the concentration range of 5ppm-50ppm. The recovery at three concentrations were above 90,1\%. The limit of detection (LOD) and limit of quantification (LOQ) of the methods were 3 and $10 \mathrm{mg} / \mathrm{kg}$, respectively. All obtained results were acceptable according to the AOAC for dietary supplements. The method was applied to analyze 34 samples in Hanoi.

Keywords: Crinamidine, Gas chromatography tandem mass spectrometry (GS-MS/MS) 